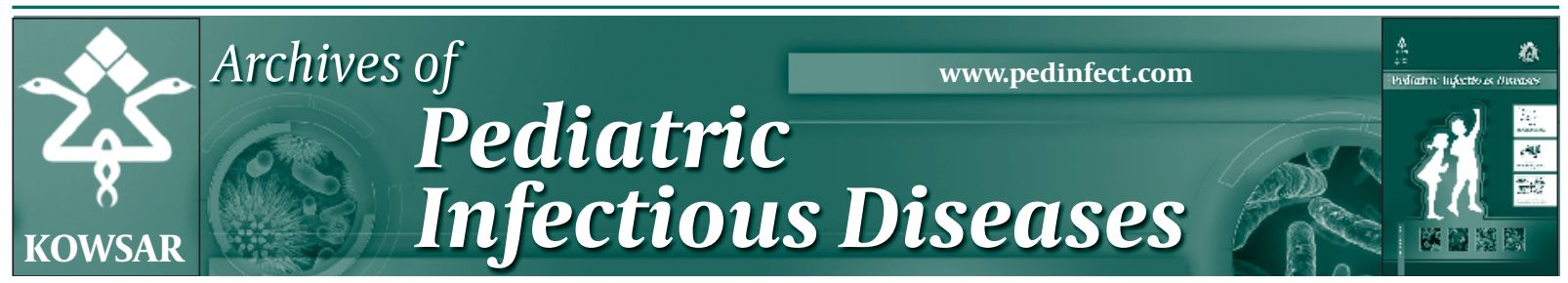

\title{
Idiopathic Thrombocytopenic Purpura Is More Severe in Children with a Re- cent History of Vaccination
}

\author{
Akbar Shafiee ${ }^{1}$, Shiva Nazari ${ }^{2,}$, , Arsalan Hashemiaghdam ${ }^{3}$, Mohammad Taghi Sadeghi- \\ Koupai $^{4}$ \\ ${ }^{1}$ Tehran Heart Center, Tehran University of Medical Sciences, Tehran, IR Iran \\ ${ }^{2}$ Pediatric Congenital Hematologic Disorders Research Center, Shahid Beheshti University of Medical Sciences, Tehran, IR Iran \\ ${ }^{3}$ Faculty of Medicine, Tehran University of Medical Sciences, Tehran, IR Iran \\ ${ }^{4}$ Faculty of Paramedical Sciences, Shahid Beheshti University of Medical Sciences, Tehran, IR Iran \\ ${ }^{*}$ Corresponding author: Shiva Nazari, Pediatric Congenital Hematologic Disorders Research Center, Shahid Beheshti University of Medical Sciences, Shari- \\ ati Ave, 1983963113, Tehran, IR Iran. Tel:+98-2122227021; Ext: 9, Fax:+98-2122220254. E-mail: Shnazari2000@yahoo.com.
}

\begin{abstract}
A B S T R A C T
Background: Idiopathic thrombotic thrombocytopenia (ITP) the most common cause of acute onset thrombocytopenia in children, can be classified as primary (idiopathic) or secondary to different causal agents (drugs, vaccination, infections).

Objectives: This study is aimed to observe the severity of ITP based on the probable cause of the disease, specifically vaccination.

Patients and Methods: This retrospective observational study surveyed the records of all patients, aged 1 to6 months, who were admitted with the diagnosis of ITP at Mofid Children's hospital in a 5 year period (2005-2010). Based on history of recent vaccination ( $<6$ weeks), patients were divided into two groups. The severity of ITP, described by the platelet count, was then compared between the recently vaccinated and not recently vaccinated groups. Severe ITP was defined as platelet count below $20,000 / \mathrm{mm}^{3}$. All ITP patients with concomitant diseases, diagnoses other than ITP, or simultaneous history of vaccination and probable virus infection were excluded.

Results: 51 patients were enrolled in this study (mean age $=3.86 \pm 1.53$ months; males $=32$ [62.7\%]). In $33(64.7 \%$ ) patients the platelets level was below $20000 / \mathrm{mm}^{3}$. Thrombocytopenia following vaccination was observed in 25 (49\%) patients. The number of patients with platelet count below $20000 / \mathrm{mm}^{3}$ was significantly higher in the recently-vaccinated group (P value $=0.006$ ). ITP was more frequent in the recently vaccinated children under ${ }^{3}$ months of age (PValue $=0.03$ ).

Conclusions: In this study, a higher rate of more severe ITP in recently vaccinated young children was observed in comparison with other probable etiologies. Further investigations are needed to explain this finding.
\end{abstract}

Keywords: Purpura, Thrombocytopenic, Idiopathic; Vaccination; Child

Copyright ( $\odot$ 2013, Kowsar Corp.; Published by Kowsar Corp.

-Article type: Research Article; Received: 26 Dec 2012, Revised: 02 Mar 2013, Accepted: 16 Apr 2013; DOI: 10.5812/pedinfect.9971

-Implication for health policy/practice/research/medical education:

Findings of this study could help to make policies to prevent ITP following Vaccination.

-Please cite this paper as:

Shafiee A, Nazari S, Hashemiaghdam A, Sadeghi-Koupai MT. Idiopathic Thrombocytopenic Purpura Is More Severe in Children with a Recent History of Vaccination. Arch Pediatr Infect Dis.2013;1(3):113-7. DOI:10.5812/pedinfect.9971

Copyright (C) 2013, Kowsar Corp.; Published by Kowsar Corp.

This is an Open Access article distributed under the terms of the Creative Commons Attribution License (http://creativecommons.org/licenses/by/3.0), which permits unrestricted use, distribution, and reproduction in any medium, provided the original work is properly cited. 


\section{Background}

The most common cause of acute onset thrombocytopenia in an otherwise healthy child is idiopathic thrombocytopenic purpura (ITP) (1). Visible symptoms of ITP include the spontaneous formation of petechiae and purpura, especially on the extremities, bleeding from the nostrils or at the gums and menorrhagia. Which between them, the latter occurs if the platelet count is below 20,000 per $\mathrm{mm}^{3}(2,3)$. ITP can be classified as primary (idiopathic), or secondary to different causal agents (drugs, vaccination, infections) $(4,5)$. The primary treatment goal is more to prevent severe bleeding rather than achieving normal platelet counts. The incidence of ITP is estimated at 50-100 new cases per million per year (6, 7). ITP in children is usually self-limiting, with a typically acute onset and frequently occurring a few days or weeks after viral infection or vaccination (8-12). At least 70 percent of childhood cases will end up in remission within six months, even without treatment $(7,13-16)$.

Thrombocytopenia resolving before 6 months is called acute and is mostly observed in children. The male to female ratio in childhood cases are roughly equal for both genders $(16,17)$.

The clinical picture of post-vaccination ITP is believed to be similar to that of childhood ITP (18). Acute ITP was considered to be associated with the use of a vaccine in case there was no recognized etiology and the interval between vaccination and onset of acute ITP symptoms was within 5 weeks (19). However, none of the routine childhood vaccines given in the first year of life was known to be significantly associated with an increased risk of ITP (20). Studies reporting a link between MMR vaccination and ITP have been criticized because concomitant viral infections have not usually been excluded. ITP appears to arise following the measles, mumps, and rubella vaccine, although the incidence is very rare $(18,21,22)$.

\section{Objectives}

This study goal was to observe the severity of clinical manifestations of ITP among 1-6 month old children admitted to Mofid Children's hospital within a 5 year period, based on probable etiologies of the disease.

\section{Patients and Methods}

This retrospective observational study surveyed the records of all patients, aged from 1 month to 6 months, who were admitted with the diagnosis of ITP at Mofid Children's hospital in a 5 year period from March 2005 untillMarch 2010. Exclusion criteria included concomitant infectious disease, renal impairment, hepatic disease, blood dyscrasia, or diagnoses other than ITP. Also those who had a recent history of vaccination and suspicious viral infection simultaneously were excluded.

Severe ITP was defined as platelet count below 20,000/ $\mathrm{mm}^{3}$. Studied variables included: demographic characteristics, platelets counts at the time of admission, one month after the diagnosis and 6 months after the treatment and result of the bone marrow aspiration (BMA).

Based on the presence of a history of recent vaccination in less than 6 weeks before the diagnosis of ITP or more than 6 weeks, patients were divided in to two groups and the severity of ITP based on platelet count was then compared between the recently vaccinated and not recently vaccinated groups.

Collected data were analyzed using SPSS software (version 15.0, Chicago, IL, USA). The data for continuous variables were reported as means \pm standard deviation. For intergroup comparisons, the Chi-square test was used. The Mann-Whitney U-test and Student T-test were subsequently used for comparing group means. A P-value below 0.05 was considered significant.

\section{Results}

A total of 51 patients were eligible to enter this observational study (Mean age $=3.86 \pm 1.53$ months; males $=32$ [62.7\%]). Median age of the children was 3 months and infants between 1 to 3 months were the largest age group. In 33 patients (64.7\%) platelet level was under $20,000 / \mathrm{mm}^{3}$. General characteristics of the patients are summarized in Table 1. No death or intracranial bleeding was reported in the study population.

\begin{tabular}{|c|c|}
\hline Characteristic $^{a}$ & Total Population $(n=51)$ \\
\hline Age, $d^{b}$ & $41.5(1-180)$ \\
\hline Male Gender, No.(\%) & $32(62.7)$ \\
\hline Baseline platelet count, $/ \mathrm{mm}^{3}$ & $15150.50(1000-32000)$ \\
\hline $\begin{array}{l}\text { Platelet count after } 1 \text { month, / } \\
\text { mm }^{3}\end{array}$ & $\begin{array}{l}183700.00(26000.00- \\
460000.00)\end{array}$ \\
\hline $\begin{array}{l}\text { Platelet count after } 6 \text { months, } \\
/ \mathrm{mm}^{3}\end{array}$ & $\begin{array}{l}221360.00(39000.00- \\
594000.00)\end{array}$ \\
\hline $\begin{array}{l}\text { Platelet count less than } 20000 / \\
\mathrm{mm}^{3}\end{array}$ & $33(64.7)$ \\
\hline $\begin{array}{l}\text { Rise of platelet count after } 1 \\
\text { month, No.(\%) }\end{array}$ & $7(13.7)$ \\
\hline
\end{tabular}

Rise ofmegacaryocytes, No.(\%) $\quad 48(94.1)$

a Data are shown as frequency (percentage) or median (min, max).

${ }^{\mathrm{b}}$ Age by days

History of recent vaccination was detected in 25 (49\%) patients and there was no history of vaccination within the past 6 weeks in 26 (51\%) patients. There was a significant difference between the recently vaccinated and not recently vaccinated group regarding platelet count $(\mathrm{P}=$ 0.006 ) (Table 2). Also, more patients had platelet counts less than $20,000 / \mathrm{mm}^{3}$ in the recently-vaccinated ITP 
group $(\mathrm{P}=0.08)$. Platelet count after one month was significantly lower in the recently vaccinated group $(\mathrm{P}=$
0.03), although there was no meaningful difference in platelet counts after 6 months.

\begin{tabular}{|c|c|c|c|}
\hline Characteristic $^{\mathrm{a}}$ & Recently-Vaccinated $(\mathrm{n}=25)$ & Not-recently Vaccinated $(\mathrm{n}=26)$ & P-value \\
\hline Age, $d$ & $40.3(1-180)$ & $41.4(1-180)$ & 0.24 \\
\hline Male Gender, No. (\%) & $14(56.0)$ & $18(69.0)$ & 0.33 \\
\hline Baseline platelet count, $/ \mathrm{mm}^{3}$ & $14000(1000-23500)$ & $18000(8000-32000)$ & 0.006 \\
\hline Platelet count after 1 month, $/ \mathrm{mm}^{3}$ & $17500(26000-460000)$ & $190000(29000-410000)$ & 0.03 \\
\hline Platelet count after 6 month, $/ \mathrm{mm}^{3}$ & $220000(39000-520000)$ & $235000(45000-594000)$ & 0.16 \\
\hline Platelet counts less than 20000, No. (\%) & $19(76.0)$ & $14(53.8)$ & 0.08 \\
\hline Rise of platelet after 1 month, No. (\%) & $4(16.0)$ & $3(11.5)$ & 0.47 \\
\hline Rise ofmegacaryocytes,No. (\%) & $24(96.0)$ & $24(92.6)$ & 0.87 \\
\hline
\end{tabular}

${ }^{\mathrm{a}}$ Data are shown as frequency (percentage) or median (min- max).

Only one patient in the recently vaccinated group had serious bleeding and received blood transfusion. Bone marrow aspiration showed an increase in the number of megacaryocytes in 48 (94.1\%) patients without any significant difference between the two groups.

Treatment options in the study population included corticosteroids in (46.3\%) patients, intravenous immunoglobulin (IVIG) in (74.3\%) patients and anti-D immunoglobulin in (6.6\%) patients. No drug complication was reported in the study population. Response to treatment as described by platelet count at the end of the first month was not different between the groups. In other words, the rise of platelet count after one month was not significantly different between the recently vaccinated and not recently vaccinated group $(\mathrm{P}=0.47)$.

Moreover, rise of megacaryocytes was not statistically different between the two groups $(\mathrm{P}=0.87)$.

Those who had hemorrhagic symptoms were treated with Cyclosporine (86.1\%), IVIG (13.9\%), Danazol (13.9\%), Anti-D (11.1\%), Interferon A (5.6\%), Vincristin (2.8\%), Azatioprin (2.8\%) and Anti CD20 antibody (2.8\%). In case of inappropriate response to initial treatment, patients received combination therapy. Type of prescribed medications did not have any significant influence on the time to remission or platelet level after one month in both groups.

\section{Discussion}

This Study aimed to observe the relation between the etiology and clinical characteristics of primary ITP in infants aged between 1 to 6 months, by reviewing the records of surviving patients at Mofid Children's hospital within a 5 year period. It was observed that vaccinerelated ITP results in more severe clinical manifestations in compared to other ITP etiologies.

In Iran, 11 children are vaccinated with OPV, HBV vaccine and BCG at birth. They receive OPV and DPT at 2, 4 and 6 months of age and HBV vaccine again at 2 and 6 months of age. Although we did not find an increased risk of ITP for any of the commonly given childhood vaccines, there was a significant relationship between a recent history of vaccination and severity of the acute disease in comparison with other probable etiologies. MMR has been proposed as the culprit in young children with an incidence of 1 to 3 children every 100,000 vaccine doses (5,12, 23-25); however, MMR is injected at 12 and 18 months of age and this vaccine cannot be considered as the cause of ITP in the current study population. Development of ITP following other vaccines, particularly DPT, is restricted to few cases and the data is insufficient to assume a causal relationship (12, 26, 27). Several epidemiologic studies have been performed about ITP in children (20), however, they have not explored the severity of the disease based on the probable etiology (5).

Age and gender are the two most important factors in all studies about ITP in children (28). Although a female predominance is reported in previous studies (29), there was not a significant difference in our study population regarding gender. ITP is self-limiting and not life-threatening in most cases (4). Although complications of ITP in children are rare, they can be dangerous (30). In our study, no serious complication was observed. This may be due to early diagnosis and admission in the hospital.

In cases with platelet count $<10000 / \mathrm{mm}^{3}$, steroids may be prescribed without any proven benefit (30). IVIG is suggested as the drug of choice by the American Society of Hematology, although it has no benefit over corticosteroids (31). There are no data showing that the treatment affects either short or long term clinical outcome of ITP $(30,32)$. In our study, there was no significant difference between the prescribed medications regarding time to remission and rise of platelet counts after one month.

Few cases have been reported to demonstrate a drop in the platelet count following the vaccine repeat $(33,34)$. However, there are more reports showing no evidence of recurring of 
post vaccination ITP after repeating the vaccination $(35,36)$. In this study, we considered duration of 6 weeks from the vaccination to the onset of the ITP syndromes. On the other hand, the vaccination intervals based on the national Vaccination Program is 2 months. Therefore, the cases that developed ITP in the last 2 weeks of the vaccination interval were considered as not recently vaccinated.

Conclusion:In this study, a higher rate of more severe ITP in recently vaccinated young children was observed, in comparison with other probable etiologies. In order to reach a more accurate result, studying the same topic on children older than 1.5 years is recommended.

\section{Acknowledgements}

This study was supported by Mofid Children's Hospital, Shahid Beheshti University of Medical Sciences, Tehran, Iran.

\section{Authors' Contribution}

None declared.

\section{Financial Disclosure}

The authors declare no conflict of interests.

\section{Funding/Support}

There is no support.

\section{References}

1. Kliegman Robert. Nelson textbook of pediatrics. 19th ed. Philadelphia, Pa.; London: Elsevier Saunders; 2011.

2. Cines DB, McMillan R. Management of adult idiopathic thrombocytopenic purpura. Annu Rev Med. 2005;56:425-42

3. Rodeghiero F. Idiopathic thrombocytopenic purpura: an old disease revisited in the era of evidence-based medicine. Haematologica. 2003;88(10):1081-7.

4. Bolton-Maggs PH. Idiopathic thrombocytopenic purpura. Arch Dis Child. 2000;83(3):220-2.

5. Bertuola F, Morando C, Menniti-Ippolito F, Da Cas R, Capuano A Perilongo $\mathrm{G}$, et al. Association between drug and vaccine use and acute immune thrombocytopenia in childhood: a case-control study in Italy. Drug Saf. 2010;33(1):65-72.

6. Watts RG. Idiopathic thrombocytopenic purpura: a 10-year natural history study at the childrens hospital of alabama. Clin Pediatr (Phila). 2004;43(8):691-702.

7. Treutiger I, Rajantie J, Zeller B, Henter JI, Elinder G, Rosthoj S. Does treatment of newly diagnosed idiopathic thrombocytopenic purpura reduce morbidity? Arch Dis Child. 2007;92(8):704-7.

8. Yong M, Schoonen WM, Li L, Kanas G, Coalson J, Mowat F, et al. Epidemiology of paediatric immune thrombocytopenia in the General Practice Research Database. Br JHaematol 2010;149(6):855-64.

9. Cines DB, Blanchette VS. Immune thrombocytopenic purpura. $N$ Engl J Med. 2002;346(13):995-1008

10. Psaila B, Bussel JB. Immune thrombocytopenic purpura. Hemato Oncol Clin North Am. 2007;21(4):743-59.

11. Le Meignen M, Mossler P, Mates M, Mathey C, Hass A, Monpoux F, et al. [Management of autoimmune thrombocytopenic purpura: a prospective study of 147 children from the regional network RHemaP]. Arch Pediatr. 2008;15(9):1398-406.

12. O'Leary Sean T, Glanz Jason M, McClure David L, Akhtar Aysha, Daley Matthew F, Nakasato Cynthia, et al. The risk of immune thrombocytopenic purpura after vaccination in children and adolescents. Pediatrics. 2012;129(2):248-255.

13. Kuhne T, Imbach P, Bolton-Maggs PH, Berchtold W, Blanchette V, Buchanan GR. Newly diagnosed idiopathic thrombocytopenic purpura in childhood: an observational study. Lancet. 2001;358(9299):2122-5

14. Glanz J, France E, Xu S, Hayes T, Hambidge S. A populationbased, multisite cohort study of the predictors of chronic idiopathic thrombocytopenic purpura in children. Pediatrics. 2008;121(3):e506-12.

15. Blanchette VS, Carcao M. Childhood acute immune thrombocytopenic purpura: 20 years later. Semin Thromb Hemost 2003;29(6):605-17

16. Buchanan GR. Thrombocytopenia during childhood: what the pediatrician needs to know. Pediatr Rev. 2005;26(11):401-9.

17. Cines DB, Bussel JB. How I treat idiopathic thrombocytopenic purpura (ITP). Blood. 2005;106(7):2244-51

18. Rajantie J, Zeller B, Treutiger I, Rosthoj S. Vaccination as sociated thrombocytopenic purpura in children. Vaccine. 2007;25(10):1838-40.

19. Wang JD, Huang FL, Chen PY, Wang TM, Chi CS, Chang TK. Acute immune thrombocytopenic purpura in infants: associated factors, clinical features, treatment and long-term outcome. Eur J Haematol. 2006;77(4):334-7.

20. O'Leary ST, Glanz JM, McClure DL, Akhtar A, Daley MF, Nakasato C et al. The risk of immune thrombocytopenic purpura after vaccination in children and adolescents. Pediatrics. 2012;129(2):248-55.

21. Farrington P, Pugh S, Colville A, Flower A, Nash J, Morgan-Capne $\mathrm{P}$, et al. A new method for active surveillance of adverse events from diphtheria/tetanus/pertussis and measles/mumps/rubella vaccines. Lancet. 1995;345(8949):567-9.

22. Wiersbitzky S, Bruns R, Muller C, Wiersbitzky H, Mentel R, Seide W. Postvaccinal thrombocytopenia: fact or myth? Pediatr Hematol Oncol.1995;12(5):503-5.

23. Cecinati Valerio, Principi Nicola, Brescia Letizia, Giordano Paola, Esposito Susanna. Vaccine administration and the developmen of immune thrombocytopenic purpura in children. Human vaccines \& immunotherapeutics. 2013;9(5):-1.

24. Miller E, Waight P, Farrington CP, Andrews N, Stowe I, Taylor B. Idiopathic thrombocytopenic purpura and MMR vaccine. Archives of disease in childhood. 2001;84(3):227-229.

25. Mantadakis Elpis, Farmaki Evangelia, Buchanan George R Thrombocytopenic purpura after measles-mumps-rubella vaccination: a systematic review of the literature and guidance for management. The Journal of pediatrics. 2010;156(4):623-628.

26. Ronchi F, Cecchi P, Falcioni F, Marsciani A, Minak G, Murator $\mathrm{G}$, et al. Thrombocytopenic purpura as adverse reaction to recombinant hepatitis B vaccine. Archives of disease in childhood. 1998;78(3):273-274.

27. Hsieh Yuh-Lin, Lin Lung-Huang. Thrombocytopenic purpura following vaccination in early childhood: experience of a medica center in the past 2 decades. Journal of the Chinese Medical Association. 2010;73(12):634-637.

28. Fogarty PF, Segal JB. The epidemiology of immune thrombocytopenic purpura. Curr Opin Hematol. 2007;14(5):515-9.

29. Schoonen WM, Kucera G, Coalson J, Li L, Rutstein M, Mowat F, et al. Epidemiology of immune thrombocytopenic purpura in the General Practice Research Database. BrJ Haematol. 2009;145(2):235-44

30. Rehman A. Immune thrombocytopenia in children with reference to low-income countries. East Mediterr Health J. 2009;15(3):729-37.

31. George JN, Woolf SH, Raskob GE, Wasser JS, Aledort LM, Ballem PJ, et al. Idiopathic thrombocytopenic purpura: a practice guideline developed by explicit methods for the American Society of Hematology. Blood.1996;88(1):3-40.

32. Mueller BU, Bennett CM, Feldman HA, Bussel JB, Abshire TC, Moore TB, et al. One year follow-up of children and adolescents with chronic immune thrombocytopenic purpura (ITP) treated with rituximab. Pediatr Blood Cancer. 2009;52(2):259-62.

33. Oski FA, Naiman JL. Effect of live measles vaccine on the platele 
count. N Engl J Med.1966;275(7):352-6.

34. Beeler J, Varricchio F, Wise R. Thrombocytopenia after immunization with measles vaccines: review of the vaccine adverse events reporting system (1990 to 1994). Pediatr Infect Dis J.1996;15(1):88-90.

35. Sauve LJ, Bettinger J, Scheifele D, Halperin S, Vaudry W, Law B.
Postvaccination thrombocytopenia in Canada. Pediatr Infect Dis J. 2010;29(6):559-61.

36. Stowe J, Kafatos G, Andrews N, Miller E. Idiopathic thrombocytopenic purpura and the second dose of MMR. Arch Dis Child. 2008;93(2):182-3. 